\section{U.S. Consumer Purchases and Nutritional Knowledge of Pecans}

\author{
Jay M. Lillywhite ${ }^{1,3}$, Jennifer E. Simonsen ${ }^{1}$, \\ and Richard J. Heerema ${ }^{2}$
}

Additional InDEX wORDs. Carya illinoinensis, preferences, tree nuts

SumMary. The U.S. pecan (Carya illinoinensis) industry is important to the country in both economic and cultural terms. Although the industry has expanded its export markets considerably, domestic pecan consumption has remained relatively flat. Expanding a domestic market is an important risk management strategy. To diversify, industry stakeholders may need to focus effort on growing domestic demand for pecans and pecan products, yet relatively little is known about U.S. pecan consumers because the majority of available information is garnered from supply side (production) data. This study used a web-based panel survey of 1009 U.S. food consumers to explore the demographics of pecan consumers, gauge their current tree nut nutrition knowledge, and examine the preferences surrounding their pecan purchases. Almost three-quarters (74\%) of survey respondents consume pecans; demographic differences were observed between respondents who consume pecans and those who do not. Respondents' knowledge of general and tree nut nutrition concepts varied. Respondents most frequently purchase pecans from a grocery store, buy them shelled as a raw ingredient for baking/cooking, and consume pecans four to six times per year.

$\mathrm{T}$ Tree nuts are a popular food in the United States, used as both a stand-alone snack and as ingredients in other food dishes. Common tree nuts, such as almonds (Prunus dulcis), pecans, and walnuts (Juglans regia), have a number of nutritional benefits that may be attractive to food consumers. For example, consumption of tree nuts may reduce the risk of coronary heart disease (Kris-Etherton et al., 2008) and cardiovascular heart disease (Blomhoff et al., 2006). These nutritional benefits may vary depending on the nut type because the underlying nutritional components, such as lipid and antioxidant content, also vary (e.g., Carlsen et al., 2010; Robbins et al., 2011). U.S. tree nut industries have attempted to capitalize on the nutritional aspects of their products by incorporating health messages into their marketing. An example of a wellknown campaign is that of the Blue Diamond Almond growers cooperative, which promotes the healthfulness

This research was made possible through the support of New Mexico State University's Agricultural Experiment Station.

${ }^{1}$ Department of Agricultural Economics \& Agricultural Business, New Mexico State University, P.O. Box 30003, MSC 3169, Las Cruces, NM 88003

${ }^{2}$ Department of Extension Plant Sciences, New Mexico State University, P.O. Box 30003, MSC 3AE, Las Cruces, NM 88003

${ }^{3}$ Corresponding author. E-mail: lillywhi@nmsu.edu. of almonds and provides healthrelated educational material on the cooperative's website (Blue Diamond Growers, 2014). Providing education about the nutritional benefits of food products may influence consumers' preferences and purchasing habits (e.g., Chu et al., 2009; Freedman and Connors, 2010; James et al., 2009). Other U.S. tree nut industries [i.e., hazelnut (Corylus avellana), pistachio (Pistacia vera), walnut, and pecan] have also applied similar strategies to promote domestic consumption, with varying success as measured by increases in per capita consumption over the past decade (U.S. Department of Agriculture, 2013).

Although domestic (United States) per capita almond consumption has increased 5-fold since 1976, pecan consumption has remained relatively flat over the past three and a half decades. The pecan industry has focused its efforts on expanding export markets, with U.S. pecan exports growing by almost $2000 \%$ since 1980 . The primary pecan export market, Hong Kong (a conduit to Asian markets), has experienced rapid expansion since 2004 and has been instrumental in increasing U.S. pecan prices despite flat domestic demand.

High export prices obtained over the last several years may be at risk for several reasons, including economic uncertainty in popular export markets (e.g., China) expressed in various popular press outlets (e.g., Harjani, 2014; Silk, 2013; Wassener, 2013) and increased production in developing markets (e.g., Mexico and China), as well as U.S. acreage. For example, pecan acreage in Mexico has increased, on average, over 10,000 acres (4046.9 ha) per year during the last decade (Servicio de Información Agroalimentraria y Pesquera, 2012). One approach to managing these potential risks is to focus effort on growing domestic demand for pecans and pecan products in addition to the work that is taking place in foreign markets. Relatively little is known about U.S. pecan consumers because the majority of available information is garnered from supply side (production) data rather than demand-side data. Consumer and potential consumer information can provide valuable marketing insights for stakeholders looking to expand domestic pecan sales.

This study seeks to expand the exploratory work of Lombardini et al. (2008), who investigated consumers' pecan nutrition knowledge and purchases using a small convenience sample of U.S. respondents. Our study provides a more detailed exploratory attempt at gathering demand-related information by learning more about pecan consumers-who they are and their tree nut nutrition knowledge, preferences and purchase habits-to develop a more comprehensive picture of the demand side of the U.S. pecan market. More specifically, this study seeks to 1) explore the demographics of pecan consumers, 2) gauge their current tree nut nutrition knowledge, and 3) examine the preferences surrounding their tree nut and pecan purchases.

\section{Materials and methods}

An online panel survey was conducted 24-28 Oct. 2013 to collect primary data regarding consumers' pecan preferences and purchase behavior. The survey instrument was split into three sections to collect information on 1) respondents' general and tree nut nutrition knowledge, 2 ) pecan purchases and preferences, and 3 ) demographic characteristics of the respondents. Nutrition knowledge was measured using statements previously applied in scholarly literature for this purpose (e.g., Hoogenboom et al., 
2009; Pawlak et al., 2009). These questions were used as a measure of each food consumer's general and tree nut-specific nutrition knowledge levels. Survey respondents were members of a group of online market research panels managed by Cint, an independent global market research corporation with U.S. offices in Atlanta, GA, and Los Angeles, CA. The market research company provided a small measure of compensation (i.e., \$0.50$\$ 2.00$ cash incentive) to respondents for their participation in market research surveys. Survey respondents were required to be at least 18 years of age. A sample of 9299 panelists (representative of the United States in terms of U.S. Census region of residence) was invited to participate in the survey via e-mail to meet a sample quota of 1000 respondents (sample quota was determined by the research project budget), and a total of 1009 responses were used in the analysis.

For analysis, raw data from the web-based survey were collected using an electronic spreadsheet program, and categorical questions (e.g., multiple choice questions) were numerically coded. Simple descriptive statistical analyses (e.g., frequency tables, means), $t$ tests, analysis of variance, and chisquare tests were performed on the data using SAS statistical analysis software (version 9.2; SAS Institute, Cary, NC).

\section{Results and discussion}

DEMOGRAPHICS OF PECAN CONSUMERs. Responses were received from all 50 states. On average, respondents lived with two other individuals and had one child under the age of 18 years living at home. Additional demographic characteristics of respondents are reported in Table 1.

Chi-square tests comparing frequencies of demographic variables commonly reported at a national level suggest that survey respondents diverged from the general U.S. population in age, census region of residence, gender, income, marital status, and race (Table 1). This fact may be explained by several factors relating to the survey methodology. To comply with institutional review board policy, respondents were provided information regarding the purpose of the survey (i.e., gaining insights into consumer preferences for tree nuts) and given the opportunity to decline participation if

Table 1. Demographics of the U.S. population and of a group of respondents to a web-based survey of nutrition knowledge, pecan preferences, and pecan purchase behavior. The survey was conducted 24-28 Oct. 2013. Respondents were potential U.S. pecan consumers aged 18 years or older.

\begin{tabular}{|c|c|c|c|}
\hline \multirow[b]{2}{*}{ Attribute } & \multicolumn{2}{|c|}{ Respondents } & \multirow[b]{2}{*}{ U.S. population $(\%)^{\mathrm{z}}$} \\
\hline & (no.) & $(\%)$ & \\
\hline \multicolumn{4}{|l|}{ Age } \\
\hline Under 20 years of age & 22 & 2.2 & 26.6 \\
\hline $20-34$ years of age & 326 & 32.3 & 20.5 \\
\hline $35-54$ years of age & 386 & 38.3 & 27.4 \\
\hline $55-64$ years of age & 173 & 17.2 & 12.1 \\
\hline 65 years of age or older & 102 & 10.1 & 13.4 \\
\hline \multicolumn{4}{|l|}{ Annual household income } \\
\hline Less than $\$ 24,999$ & 213 & 21.1 & 24.1 \\
\hline$\$ 25,000-\$ 49,999$ & 276 & 27.4 & 24.2 \\
\hline$\$ 50,000-\$ 99,999$ & 375 & 37.2 & 30.0 \\
\hline$\$ 100,000-\$ 149,999$ & 95 & 9.4 & 12.5 \\
\hline$\$ 150,000$ or more & 50 & 5.0 & 9.2 \\
\hline \multicolumn{4}{|l|}{ Census region of residence ${ }^{y}$} \\
\hline Midwest & 261 & 25.9 & 17.8 \\
\hline Northeast & 179 & 17.7 & 21.5 \\
\hline South & 341 & 33.8 & 37.2 \\
\hline West & 228 & 22.6 & 23.4 \\
\hline \multicolumn{4}{|l|}{ Gender } \\
\hline Male & 321 & 31.8 & 49.2 \\
\hline Female & 688 & 68.2 & 50.8 \\
\hline \multicolumn{4}{|l|}{ Marital status } \\
\hline Single & 241 & 23.9 & 32.4 \\
\hline Married & 586 & 58.1 & 48.4 \\
\hline Divorced, widowed, or separated & 158 & 15.7 & 19.2 \\
\hline Other ${ }^{x}$ & 24 & 2.4 & - \\
\hline \multicolumn{4}{|l|}{ Race } \\
\hline American Indian or Alaska Native & 11 & 1.1 & 0.7 \\
\hline Asian & 60 & 6.0 & 4.8 \\
\hline Black or African American & 75 & 7.4 & 12.2 \\
\hline Hispanic or Latino & 47 & 4.7 & 16.6 \\
\hline White or Caucasian & 796 & 78.9 & 63.2 \\
\hline Other & 20 & 2.0 & 2.4 \\
\hline
\end{tabular}

${ }^{\mathrm{z} U}$ U.S. Census Bureau (2013).

yU.S. Census Bureau (2014).

${ }^{\mathrm{x}}$ Category not used by U.S. Census Bureau.

they were not interested in the topic. As a result of this policy, it is possible, and even likely, that survey participants had some affinity for tree nuts, pecans, or both. Since tree nut consumers are a subset of the U.S. population, it is not surprising that demographic features differed between the sample and the U.S. population.

Similarly, since the survey protocol required all participants to be at least 18 years of age, there was some disparity between the sample frequency for age and age frequencies for the general population. It is valuable to explore the information gained from this survey because these respondents may be representative of pecan consumers or those interested in pecans, and inferences to the general population should be made with awareness of the limitations of the survey methodology used here. Further research should be conducted to validate and extend the findings presented here.

Almost three-quarters (74.0\%) of survey respondents reported they consume pecans on a regular basis. Chi-square tests of proportion were used to explore differences between these respondents who consume pecans on a regular basis and those who do not (Tables 2 and 3). Results suggest pecan consumers are more likely to be older: among respondents 55 years of age or older, a higher proportion consume pecans than those who do not $(P<0.05)$. A higher proportion of African Americans and Hispanics consume pecans than those who do not 
Table 2. Differences in demographic attributes between survey respondents who consume pecans on a regular basis and those respondents who do not consume pecans on a regular basis. Respondents were potential U.S. pecan consumers aged 18 years or older who participated in a web-based survey of nutrition knowledge, pecan preferences, and pecan purchase behavior. The survey was conducted 24-28 Oct. $2013(n=1009)$.

\begin{tabular}{|c|c|c|c|c|}
\hline Attribute & $\begin{array}{l}\text { Does not } \\
\text { consume } \\
\text { pecans }(\%)\end{array}$ & $\begin{array}{l}\text { Consumes } \\
\text { pecans (\%) }\end{array}$ & Total $^{\mathrm{z}}$ & Chi-square $P$ \\
\hline \multicolumn{5}{|l|}{ Age } \\
\hline Under 20 years of age & 45.5 & 54.6 & 100.1 & \multirow[t]{5}{*}{0.0082} \\
\hline $20-34$ years of age & 31.0 & 69.0 & 100.0 & \\
\hline $35-54$ years of age & 24.6 & 75.4 & 100.0 & \\
\hline $55-64$ years of age & 21.4 & 78.6 & 100.0 & \\
\hline 65 years of age or older & 18.6 & 81.4 & 100.0 & \\
\hline \multicolumn{5}{|l|}{ Annual household income } \\
\hline Less than $\$ 24,999$ & 31.9 & 68.1 & 100.0 & \multirow[t]{5}{*}{0.0297} \\
\hline$\$ 25,000-\$ 49,999$ & 24.3 & 75.7 & 100.0 & \\
\hline$\$ 50,000-\$ 99,999$ & 22.9 & 77.1 & 100.0 & \\
\hline$\$ 100,000-\$ 149,999$ & 33.7 & 66.3 & 100.0 & \\
\hline$\$ 150,000$ or more & 18.0 & 82.0 & 100.0 & \\
\hline \multicolumn{5}{|l|}{ Census region of residence ${ }^{y}$} \\
\hline Midwest & 25.3 & 74.7 & 100.0 & \multirow[t]{4}{*}{0.0015} \\
\hline Northeast & 36.3 & 63.7 & 100.0 & \\
\hline South & 20.5 & 79.5 & 100.0 & \\
\hline West & 26.8 & 73.3 & 100.1 & \\
\hline \multicolumn{5}{|l|}{ Marital status } \\
\hline Single & 31.5 & 68.5 & 100.0 & \multirow[t]{4}{*}{0.1474} \\
\hline Married & 24.1 & 75.9 & 100.0 & \\
\hline Divorced, widowed, or separated & 25.3 & 74.7 & 100.0 & \\
\hline Other & 20.8 & 79.2 & 100.0 & \\
\hline \multicolumn{5}{|l|}{ Race } \\
\hline American Indian or Alaska Native & 36.4 & 63.6 & 100.0 & \multirow[t]{6}{*}{0.0245} \\
\hline Asian & 33.3 & 66.7 & 100.0 & \\
\hline Black or African American & 13.3 & 86.7 & 100.0 & \\
\hline Hispanic or Latino & 21.3 & 78.7 & 100.0 & \\
\hline White or Caucasian & 26.3 & 73.7 & 100.0 & \\
\hline Other & 45.0 & 55.0 & 100.0 & \\
\hline \multicolumn{5}{|l|}{ Gender } \\
\hline Male & 27.4 & 72.6 & 100.0 & \multirow[t]{2}{*}{0.4736} \\
\hline Female & 25.3 & 74.7 & 100.0 & \\
\hline
\end{tabular}

${ }^{\mathrm{z}}$ Due to rounding, may not total $100 \%$.

yU.S. Census Bureau (2014).

$(P<0.05)$. Pecans also appear to be more widely consumed in the southern United States (as defined by the "south" U.S. Census region) than other regions of the United States: a higher proportion of southern U.S. residents consume pecans than southern U.S. residents who do not $(P<$ $0.05)$. This finding is logical given that regional eating patterns exist (Nayga, 1995) and given the prevalence of pecan production in southern U.S. states. These respondents could be more familiar with the uses for and taste of pecans, as well as have increased access to pecans (e.g., backyard trees).
Pecan nutrition Knowledge. Respondents' knowledge of general nutrition concepts varied (Table 4). In general, respondents' tree nut nutrition knowledge level appeared similar to that of respondents in a previous U.S. survey of food consumers (Pawlak et al., 2009), with the majority of respondents being able to correctly identify the nutritional properties and concepts of tree nuts such as almonds, cashews (Anacardium occidentale), hazelnuts, pecans, pistachios, and walnuts (Table 5 ). Although $78 \%$ of respondents in a recent study "correctly answered a question regarding which nut was the richest source of omega-3 fatty acids" (Pawlak et al., 2009), the majority of respondents in this study could not identify the relative antioxidant values of food categories and specific tree nut types. Only slightly more than half $(58.6 \%)$ of respondents in another recent study knew that pecans contain antioxidants (Lombardini et al., 2008), indicating that food consumers may be unaware of the antioxidant properties of pecans. These findings suggest tree nut nutritional knowledge may vary depending on the nutritional compound in question. Additional education about the antioxidant properties of tree nuts, including pecans, relative to other "healthy" food choices may be needed to successfully market tree nuts using an antioxidantbased health claim.

Because nutrition knowledge level can influence perception of healthful foods (e.g., Pounis et al., 2011), the demographic factors influencing this knowledge are of interest to food industry stakeholders seeking to market healthful food products. Each respondent's answers to the tree nut nutrition knowledge questions posed in Table 5 were used to calculate a tree nut nutrition knowledge score (KS). In the case of the general nutrition KS, each respondent's score was calculated as the correct percent responses to the 11 true/false and multiple choice general nutrition knowledge questions, while in the case of the tree nut nutrition KS, each respondent's score was calculated as the percent correct responses to the 11 true/false tree nut nutrition knowledge questions [ranging from $0 \%$ to $100 \%$ (e.g., Hoogenboom et al., 2009)]. Respondents varied in their tree nut nutrition KS based on several demographic factors (Table 6). Respondents who earn less than $\$ 25,000$ annually had a lower mean KS than respondents earning between $\$ 100,000$ and $\$ 150,000$ annually $(P<0.05)$. Although this study did not examine formal education level, education level may be related to income and thus to tree nut nutrition knowledge. Moreover, educational attainment can influence food consumers' decisions to buy heart-healthy menu items (Sharma et al., 2011); this decision may be in part based on nutrition knowledge.

Respondents who consider their diet healthy or very healthy had a higher mean KS than those who consider their diet unhealthy, very unhealthy, or do 
Table 3. Differences in demographic attributes between survey respondents who consume pecans on a regular basis and those respondents who do not consume pecans on a regular basis. Respondents were potential U.S. pecan consumers aged 18 years or older who participated in a web-based survey of nutrition knowledge, pecan preferences, and pecan purchase behavior. The survey was conducted 24-28 Oct. $2013(n=1009)$.

\begin{tabular}{|c|c|c|c|}
\hline Attribute & $\begin{array}{c}\text { Do not } \\
\text { consume } \\
\text { pecans }(\%)^{\mathrm{z}}\end{array}$ & $\begin{array}{l}\text { Consume } \\
\text { pecans }(\%)^{\mathrm{z}}\end{array}$ & Chi-square $P$ \\
\hline \multicolumn{4}{|l|}{ Age } \\
\hline Under 20 years of age & 3.8 & 1.6 & \multirow[t]{6}{*}{0.01} \\
\hline $20-34$ years of age & 38.6 & 30.1 & \\
\hline $35-54$ years of age & 36.3 & 39.0 & \\
\hline $55-64$ years of age & 14.1 & 18.2 & \\
\hline \multirow[t]{2}{*}{65 years of age or older } & 7.3 & 11.1 & \\
\hline & 100.1 & 100.0 & \\
\hline \multicolumn{4}{|l|}{ Annual household income } \\
\hline Less than $\$ 24,999$ & 26.0 & 19.4 & \multirow[t]{6}{*}{0.03} \\
\hline$\$ 25,000-\$ 49,999$ & 25.6 & 28.0 & \\
\hline$\$ 50,000-\$ 99,999$ & 32.8 & 38.7 & \\
\hline$\$ 100,000-\$ 149,999$ & 12.2 & 8.4 & \\
\hline \multirow[t]{2}{*}{$\$ 150,000$ or more } & 3.4 & 5.5 & \\
\hline & 100.0 & 100.0 & \\
\hline \multicolumn{4}{|l|}{ Census region of residence ${ }^{y}$} \\
\hline Midwest & 25.2 & 26.1 & \multirow[t]{5}{*}{0.00} \\
\hline Northeast & 24.8 & 15.3 & \\
\hline South & 26.7 & 36.3 & \\
\hline \multirow[t]{2}{*}{ West } & 23.3 & 22.4 & \\
\hline & 100.0 & 100.1 & \\
\hline \multicolumn{4}{|l|}{ Gender } \\
\hline Male & 33.6 & 31.1 & \multirow[t]{3}{*}{0.47} \\
\hline \multirow{2}{*}{ Female } & 66.4 & 68.8 & \\
\hline & 100.0 & 99.9 & \\
\hline \multicolumn{4}{|l|}{ Marital status } \\
\hline Single & 29.0 & 22.1 & \multirow[t]{5}{*}{0.15} \\
\hline Married & 53.8 & 59.6 & \\
\hline Divorced, widowed, or separated & 15.3 & 15.8 & \\
\hline \multirow[t]{2}{*}{ Other } & 1.9 & 2.5 & \\
\hline & 100.0 & 100.0 & \\
\hline \multicolumn{4}{|l|}{ Race } \\
\hline American Indian or Alaska Native & 1.5 & 0.9 & \multirow[t]{7}{*}{0.02} \\
\hline Asian & 7.6 & 5.4 & \\
\hline Black or African American & 3.8 & 8.7 & \\
\hline Hispanic or Latino & 3.8 & 5.0 & \\
\hline White or Caucasian & 79.8 & 78.6 & \\
\hline \multirow[t]{2}{*}{ Other } & 3.4 & 1.5 & \\
\hline & 99.9 & 100.1 & \\
\hline
\end{tabular}

${ }^{z}$ Due to rounding, may not total $100 \%$.

yU.S. Census Bureau (2014).

not know the healthfulness of their diet $(P<0.05)$. Similarly, those who read nutrition facts panels regularly had a higher mean KS than those who do not $(P<0.05)$. These results are intuitive since food consumers who are concerned about their own health and consider their diet healthy may invest in learning more about the healthfulness of specific foods. Similar to previous research in Ireland (Lalor et al., food consumers, respondents also most frequently consumed pecans four to six times per year (Lombardini et al., 2008). Total pecan consumption could be increased if consumers can be enticed to consume pecans more frequently throughout the year (e.g., if marketing efforts that encourage consumption year-round are successful).

Most respondents purchase pecans in a grocery store (Fig. 2), suggesting that pecan promotions targeting grocery consumers may be effective at increasing domestic consumption. Point-of-purchase displays, in-store coupons, and other in-store promotions may help convince nonconsumers to try a food product or increase product purchases by current consumers (Glanz and Yaroch, 2004). The results of this study differ from those of previous research, which found that farmers' markets and other directfrom-producer outlets were used with greater frequency by consumers (Lombardini et al., 2008). This disparity may be due in part to the previous study's more limited focus on only Texas consumers who were participants in a Master Gardener program. Because Texas is a large pecanproducing state, Texas consumers would have increased access to locally grown pecans using these outlets. The results of our study may be more representative of the shopping outlet preferences of U.S. pecan consumers as a whole.

Pecans are most commonly purchased as a raw baking ingredient (Fig. 3). This finding is supported by previous research, which found that $88.4 \%$ of Texas consumers use pecans as an ingredient (Lombardini et al., 2008). Pecans are most often purchased as a minimally processed product (e.g., shelled or in pieces), although $26.4 \%$ of respondents purchase valueadded pecans (Fig. 4). Additional value-added pecan product options may represent potential domestic market expansion opportunities (e.g., value-added tree nut consumers may substitute other value-added tree nut products for a value-added pecan product if comparable options are available).

Similar to Nayga et al. (1999), who found that taste influences the consumption of grains, fruits, and vegetables, taste was identified as an important or very important reason 
Table 4. Knowledge of general nutrition concepts possessed by respondents to a web-based survey of nutrition knowledge, pecan preferences, and pecan purchase behavior. The survey was conducted 24-28 Oct. 2013. Respondents were potential U.S. pecan consumers aged 18 years or older $(n=1009)$.

\begin{tabular}{|c|c|c|c|}
\hline \multirow[b]{2}{*}{ General nutrition knowledge question } & \multirow[b]{2}{*}{ Correct answer } & \multicolumn{2}{|c|}{$\begin{array}{c}\text { Respondents } \\
\text { answering correctly }\end{array}$} \\
\hline & & (no.) & $(\%)$ \\
\hline \multicolumn{4}{|l|}{ Please indicate whether the following statements are true or false. } \\
\hline $\begin{array}{l}\text { Substitution of polyunsaturated fat for some saturated fat is recommended } \\
\text { to lower the risk of developing heart disease. }\end{array}$ & True & 713 & 70.7 \\
\hline Milk is a good supplier of calcium for all age groups. & True & 925 & 91.7 \\
\hline Meat and eggs are good sources of zinc. & True & 654 & 64.8 \\
\hline Vitamin supplementation is recommended for all physically active people. & False & 349 & 34.6 \\
\hline Consuming salt daily is an essential part of a healthy diet. & False & 456 & 45.2 \\
\hline Fresh, frozen, and canned vegetables generally all have similar nutrient values. & True & 354 & 35.1 \\
\hline Carbohydrates are not as easily and rapidly digested as protein and fat. & False & 456 & 45.2 \\
\hline \multicolumn{4}{|l|}{$\begin{array}{l}\text { Please rank the following foods in terms of their antioxidant content } \\
\text { (1 being the highest in antioxidant content). }\end{array}$} \\
\hline 1. Berries and berry products & $\# 1$ & 587 & 58.2 \\
\hline 2. Nuts and seeds & $\# 2$ & 304 & 30.1 \\
\hline 3. Fruit and fruit juices & \#3 & 253 & 25.1 \\
\hline 4. Fish and seafood & \#4 & 431 & 42.7 \\
\hline All four foods ranked correctly: & $\mathrm{N} / \mathrm{A}$ & 111 & 11.0 \\
\hline
\end{tabular}

Table 5. Knowledge of tree nut nutrition concepts possessed by respondents to a web-based survey of nutrition knowledge, pecan preferences, and pecan purchase behavior. The survey was conducted 24-28 Oct. 2013. Respondents were potential U.S. pecan consumers aged 18 years or older $(n=1009)$.

Respondents answering correctly

Tree nut nutrition knowledge question

Correct answer

(no.) (\%)

Please indicate whether these statements regarding tree nuts are true or false.

Tree nuts are high in calories.

Tree nuts are high in fat.

Tree nuts are high in dietary fiber.

Tree nuts are high in salt.

Tree nuts are high in cholesterol.

Eating tree nuts may help to lower one's risk of developing heart disease.

Eating tree nuts may help to lower one's risk of developing diabetes.

Eating tree nuts will cause weight gain.

It is possible that eating tree nuts can help prevent some cancers.

Eating tree nuts may help combat age-related brain dysfunctions.

From a nutritional standpoint, all tree nuts provide relatively the same amount of nutritional benefits.

$\begin{array}{lll}\text { True } & 515 & 51.0 \\ \text { True } & 554 & 54.9 \\ \text { True } & 893 & 88.5 \\ \text { False } & 870 & 86.2 \\ \text { False } & 748 & 74.1 \\ \text { True } & 885 & 87.7 \\ \text { True } & 768 & 76.1 \\ \text { False } & 762 & 75.5 \\ \text { True } & 803 & 79.6 \\ \text { True } & 833 & 82.6 \\ \text { False } & 335 & 33.2\end{array}$

Please rank the following nuts in terms of their antioxidant content

(1 being highest in antioxidant content).

1. Pecans

2. Walnuts

3. Hazelnuts

4. Pistachios

5. Almonds

6. Cashews

All six tree nuts ranked correctly:

\begin{tabular}{crr}
$\# 1$ & 85 & 8.4 \\
$\# 2$ & 251 & 24.9 \\
$\# 3$ & 198 & 19.6 \\
$\# 4$ & 162 & 16.1 \\
$\# 5$ & 57 & 5.7 \\
$\# 6$ & 320 & 31.7 \\
N/A & 2 & 0.2 \\
\hline
\end{tabular}


Table 6. Differences in mean tree nut nutrition knowledge score by demographic characteristics of survey respondents to a web-based survey of nutrition knowledge, pecan preferences, and pecan purchase behavior. The survey was conducted 24-28 Oct. 2013. Respondents were potential U.S. pecan consumers aged 18 years or older $(n=1009)$.

\begin{tabular}{|c|c|c|}
\hline Attribute & $\begin{array}{c}\text { Mean tree nut } \\
\text { nutrition knowledge score } \\
\end{array}$ & $P>|t|$ or $F$ \\
\hline \multicolumn{3}{|l|}{ Age } \\
\hline Under 20 years of age & 66.9 & 0.06 \\
\hline $20-34$ years of age & 70.8 & \\
\hline $35-54$ years of age & 71.3 & \\
\hline $55-64$ years of age & 73.8 & \\
\hline 65 years of age or older & 74.2 & \\
\hline \multicolumn{3}{|l|}{ Annual household income } \\
\hline Less than $\$ 25,000$ & $69.4^{*}$ & 0.03 \\
\hline$\$ 25,000-\$ 49,999$ & 71.1 & \\
\hline$\$ 50,000-\$ 99,999$ & 72.6 & \\
\hline$\$ 100,000-\$ 149,999$ & $75.0 *$ & \\
\hline$\$ 150,000$ or more & 72.9 & \\
\hline \multicolumn{3}{|l|}{ Census region of residence ${ }^{y}$} \\
\hline Midwest & 71.1 & 0.38 \\
\hline Northeast & 72.7 & \\
\hline South & 71.1 & \\
\hline West & 72.9 & \\
\hline \multicolumn{3}{|l|}{ Considers diet healthy or very healthy } \\
\hline No & 70.0 & 0.00 \\
\hline Yes & 73.8 & \\
\hline \multicolumn{3}{|l|}{ Consumes pecans } \\
\hline No & 70.2 & 0.07 \\
\hline Yes & 72.3 & \\
\hline \multicolumn{3}{|c|}{ Family history of heart disease, cancer, high blood pressure, or diabetes } \\
\hline No & 70.5 & 0.05 \\
\hline Yes & 72.5 & \\
\hline \multicolumn{3}{|l|}{ Gender } \\
\hline Female & 72.6 & 0.02 \\
\hline Male & 70.1 & \\
\hline \multicolumn{3}{|l|}{ Marital status } \\
\hline Single & 68.0 & 0.00 \\
\hline Married & 73.3 & \\
\hline Divorced, widowed, or separated & 72.6 & \\
\hline Other & 68.2 & \\
\hline \multicolumn{3}{|l|}{ Race } \\
\hline American Indian or Alaska Native & 71.1 & 0.49 \\
\hline Asian & 72.9 & \\
\hline Black or African American & 68.2 & \\
\hline Hispanic or Latino & 71.4 & \\
\hline White or Caucasian & 72.1 & \\
\hline Other & 71.4 & \\
\hline \multicolumn{3}{|l|}{ Regularly reads nutrition facts panel } \\
\hline No & 67.9 & 0.00 \\
\hline Yes & 74.5 & \\
\hline
\end{tabular}

${ }^{2}$ Calculated as $\%$ of true/false questions reported in Table 5 answered correctly by respondent.

'U.S. Census Bureau (2014).

*indicates statistically significantly different means $(P<0.05)$ using Duncan's test.

for consuming tree nuts by $89 \%$ of survey respondents in this study (Table 7). Nutritional and health aspects were also important tree nut consumption drivers to $77 \%$ and $69 \%$ of respondents, respectively. This finding supports the work of
Pawlak et al. (2009), who found that North Carolinian Special Supplemental Nutrition Program for Women, Infants, and Children participants agreed that nuts should be consumed because they are healthful.
More than one-fifth $(22.4 \%)$ of respondents do not make a conscious effort to consume or purchase tree nuts (Table 8 ). These respondentsin addition to the $4.4 \%$ of respondents who do not currently consume tree nuts but are not allergic to them-also represent a potential new domestic market segment for the pecan industry. Previous research suggests pecan purchasers often buy pecans during the holiday season (Lombardini et al., 2008). Consumers who only eat tree nuts during the holidays $(22.4 \%$ of respondents to this survey) may be influenced to expand their nut consumption to other times of the year.

\section{Conclusions}

This study used an online panel survey of 1009 respondents to explore the demographics of pecan consumers, gauge their current tree nut nutrition knowledge, and examine the preferences surrounding their tree nut and pecan purchases. Respondents who do not consume pecans on a regular basis were most frequently married, Caucasian, female, between 20 and 34 years of age, earn between $\$ 50,000$ and $\$ 99,999$ annually, and reside in the southern United States. In general, respondents could be further educated about nutrition and specifically about the nutritional benefits of pecans. Respondents most frequently purchase pecans from a grocery store, buy them shelled as a raw ingredient for baking/cooking, and consume pecans four to six times per year. Although the majority of respondents consume pecans on a regular basis (74\%), less than consistent purchases throughout the year suggest these respondents may increase their per capita pecan consumption if increases in consumption throughout the year are attained.

This study examined the demand side of the domestic pecan market in an attempt to identify preferences and purchasing habits that may be used to develop additional domestic marketing strategies. This study should be considered exploratory in nature and additional research is needed to confirm its findings. Moreover, it is important to note that at high prices, marketing strategies aimed at increasing domestic demand changes may realize limited success because consumers may substitute another tree nut for pecans when prices are high 


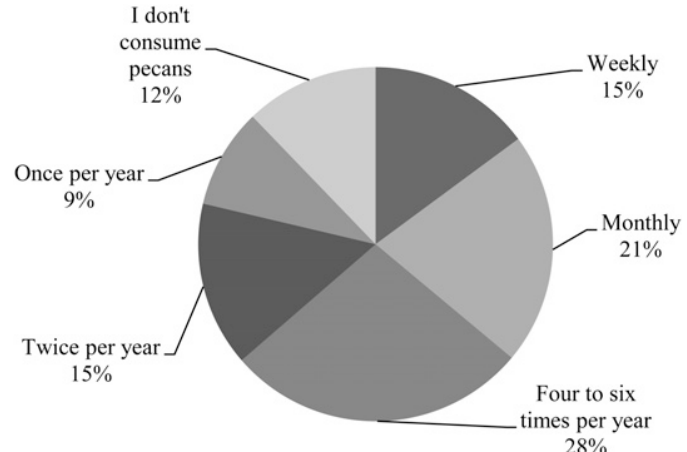

Fig. 1. Pecan consumption frequency reported by respondents to a web-based survey of potential U.S. pecan consumers $(n=1009)$.

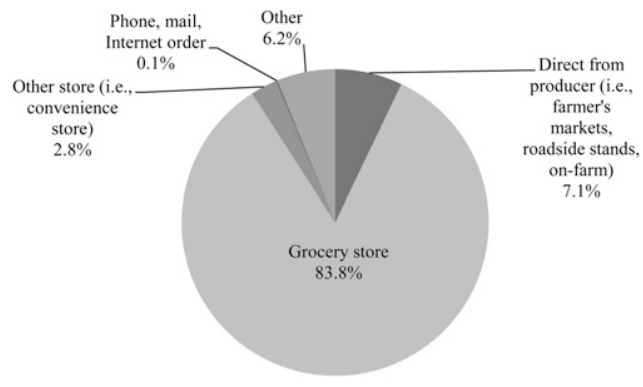

Fig. 2. Primary shopping outlets used by respondents to a web-based survey of potential U.S. pecan consumers who regularly purchase pecans $(n=747)$.

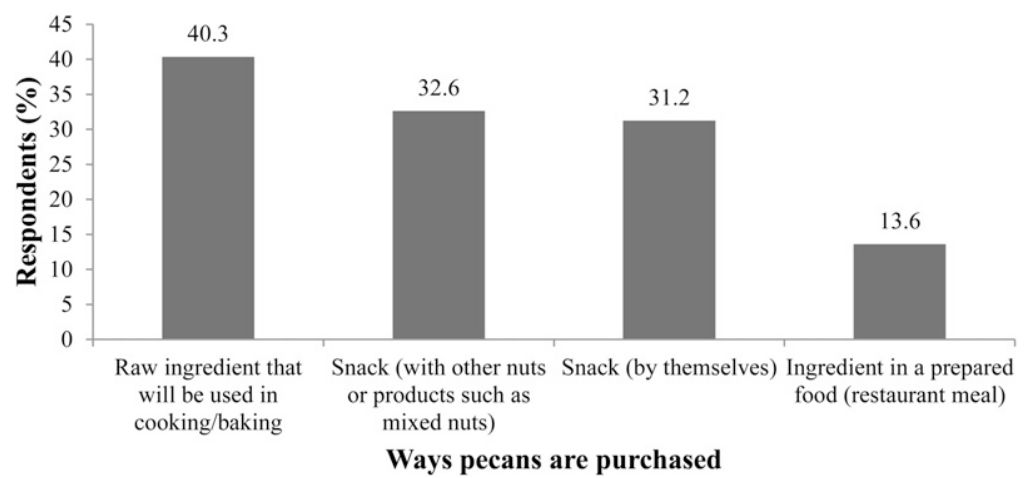

Fig. 3. Most common use of pecans purchased by respondents to a web-based survey of potential U.S. pecan consumers who consume pecans on a regular basis $(n=747)$.

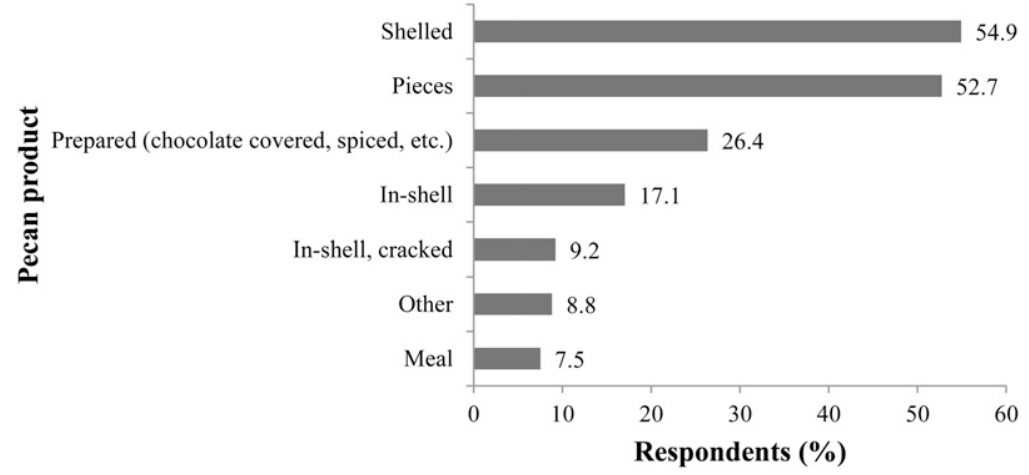

Fig. 4. Percent of respondents to a web-based survey of potential U.S. pecan consumers purchasing specific pecan products $(n=747)$. (e.g., walnuts for baking, almonds or pistachios for snacking). Further research using scanner data and other quantitative demand metrics would be valuable to validate these findings as they relate to U.S. consumers as a whole. Although food choices are complex and nutrition information cannot be the only tool used to promote healthy eating decisions (Vaandrager and Koelen, 1997), a food product's nutritional characteristics and the way these characteristics are presented (i.e., label claim) may influence purchase decisions (e.g., Kim et al., 2012; Muth et al., 2013; Visschers and Siegrist, 2010). Additional research is needed to better understand what nutritional components of pecans are most valued by consumers and how the type of marketing used to promote these components influences consumers' preferences for pecans.

\section{Literature cited}

Blomhoff, R., M.H. Carlsen, L. Frost Andersen, and D.R. Jacobs, Jr. 2006. Health benefits of nuts: Potential role of antioxidants. Brit. J. Nutr. 96(Suppl. 2): S52-S60.

Blue Diamond Growers. 2014. Blue Diamond Growers: Your health. 3 Mar. 2014. <http://bluediamond.com/ index.cfm? navid $=5>$.

Carlsen, M.H., B.L. Halvorsen, K. Holte, S.K. Bohn, S. Dragland, L. Sampson, C. Willey, H. Senoo, Y. Umezono, C. Sanada, I. Barikmo, N. Berhe, W.C. Willett, K.M. Phillips, D.R. Jacobs, Jr., and R. Blomhoff. 2010. The total antioxidant content of more than 3100 foods, beverages, spices, herbs and supplements used worldwide. Nutr. J. 9(3):1-11.

Chu, Y.H., E.A. Frongillo, S.J. Jones, and G.L. Kaye. 2009. Improving patrons' meal selections through the use of pointof-selection nutrition labels. Amer. J. Public Health 99(11):2001-2005.

Freedman, M.R. and R. Connors. 2010. Point-of-purchase nutrition information influences food-purchasing behaviors of college students: A pilot study. J. Amer. Dietetic Assn. 110(suppl. 5):S42-S46.

Glanz, K. and A.L. Yaroch. 2004. Strategies for increasing fruit and vegetable intake in grocery stores and communities: Policy, pricing, and environmental change. Prev. Med. 39(Suppl. 2):S75-S80.

Harjani, A. 2014. China 'major' uncertainty facing global economy: Soros. 13 Jan. 2014. <http://www.cnbc.com/ id/101307179>. 
Table 7. Drivers of tree nut consumption reported by respondents to a web-based survey of nutrition knowledge, pecan preferences, and pecan purchase behavior. The survey was conducted 24-28 Oct. 2013. Respondents were potential U.S. pecan consumers aged 18 years or older $(n=1009)$.

\begin{tabular}{|c|c|c|c|c|c|c|}
\hline & $\begin{array}{c}\text { Very } \\
\text { unimportant }(\%)\end{array}$ & $\begin{array}{c}\text { Unimportant } \\
(\%)\end{array}$ & $\begin{array}{c}\text { Neutral } \\
(\%)\end{array}$ & $\begin{array}{c}\text { Important } \\
(\%)\end{array}$ & $\begin{array}{c}\text { Very } \\
\text { important (\%) }\end{array}$ & $\begin{array}{c}\text { Respondents } \\
\text { (no.) }\end{array}$ \\
\hline They taste good. & 6 & 1 & 4 & 25 & 64 & 1,008 \\
\hline They are a nutritious food. & 7 & 3 & 14 & 40 & 37 & 1,007 \\
\hline $\begin{array}{l}\text { They have specific health benefits } \\
\text { I am interested in. }\end{array}$ & 6 & 5 & 26 & 33 & 29 & 1,007 \\
\hline They are a good value. & 6 & 4 & 18 & 38 & 33 & 1,009 \\
\hline
\end{tabular}

Table 8. Primary conditions under which respondents purchase or consume tree nuts. Respondents were potential U.S. pecan consumers aged 18 years or older who participated in a web-based survey of nutrition knowledge, pecan preferences, and pecan purchase behavior. The survey was conducted 24-28 Oct. $2013(n=1009)$.

I consume nuts as a part of my regular diet and make a conscious decision to eat foods that contain nuts,

I tend to only consume nuts during specific times of the year (such as during the holidays or when they are in season or on sale).

I consume nuts as a part of my regular diet, but generally do not make a conscious decision to purchase them.

For example, I consume them in breakfast cereals or restaurant meals, but my decision to purchase the food is not related to its nut content.

I consume nuts with other foods as a part of my regular diet and make a conscious decision to eat foods that contain nuts.

I do not consume tree nuts.

Hoogenboom, B.J., J. Morris, C. Morris, and K. Schaefer. 2009. Nutritional knowledge and eating behaviors of female, collegiate swimmers. North Amer. J. Sports Physical Therapy 4(3):139-148.

James, J.S., B.J. Rickard, and W.J. Rossman. 2009. Product differentiation and market segmentation in applesauce: Using a choice experiment to assess the value of organic, local, and nutrition attributes. Agr. Resource Econ. Rev. 38(3):357-370.

Kim, H., L.A. House, G. Rampersaud, and Z. Gao. 2012. Front-of-package nutritional labels and consumer beverage perceptions. Appl. Econ. Perspectives Policy 34(4):599-614.

Kris-Etherton, P., F.B. Hu, E. Ros, and J. Sabate. 2008. The role of tree nuts and peanuts in the prevention of coronary heart disease: Multiple potential mechanisms. J. Nutr. 138(9):1746S-1751S.

Lalor, F., J. Jennedy, and P.G. Wall. 2011. Impact of nutrition knowledge on behaviour towards health claims on foodstuffs. Brit. Food J. 113(6):753-765.

Lombardini, L., T.M. Waliczek, and J.M. Zajicek. 2008. Consumer knowledge of nutritional attributes of pecans and factors affecting purchasing behavior. HortTechnology 18:481-488.
Muth, M.K., C. Zhen, J. Taylor, S. Cates, K. Kosa, D. Zorn, and C. Choiniere. 2013. The value to consumers of health labeling: Statements on breakfast foods and cereals. J. Food Prod. Mktg. 19(4):279-298.

Nayga, R.M. 1995. Microdata expenditure analysis of disaggregate meat products. Rev. Agr. Econ. 17(3):275-285.

Nayga, R.M., B.J. Tepper, and L. Rosenzweig. 1999. Assessing the importance of health and nutrition related factors on food demand: A variable preference investigation. Appl. Econ. 31(12):15411549.

Pawlak, R., S. Colby, and J. Herring. 2009. Beliefs, benefits, barriers, attitude, intake and knowledge about peanuts and tree nuts among WIC participants in eastern North Carolina. Nutr. Res. Pract. $3(3): 220-225$.

Pounis, G.D., S. Makri, L. Gougias, H. Makris, M. Papakonstantinou, D.B. Panagiotakos, and M. Kapsokefalou. 2011. Consumer perception and use of iron fortified foods is associated with their knowledge and understanding of nutritional issues. Food Qual. Prefer. 22(7):683-688.

Robbins, K.S., E. Shin, R.L. Shewfelt, R.R. Eitenmiller, and R.B. Pegg. 2011.
Update on the healthful lipid constituents of commercially important tree nuts. J. Agr. Food Chem. 59(22):1208312092.

Servicio de Informacion Agroalimentraria y Pesquer. 2012. Agricultura produccion anual. 13 Jan. 2014. <www.siap. gob. $\mathrm{mx}>$.

Sharma, S., A. Wagle, K. Sucher, and N. Bugwadia. 2011. Impact of point of selection nutrition information on meal choices at a table-service restaurant. J. Foodserv. Bus. Res. 14(2):146-161.

Silk, R. 2013. China aims to maintain growth despite 'complicated' conditions. 13 Jan. 2014. <http://online.wsj.com/ news/articles/SB10001424127887323 854904578637680252436330>.

U.S. Census Bureau. 2013. 2012 American community survey 3-year estimates. 13 Jan. 2014. <http://factfinder2.census. gov/faces/nav/jsf/pages/index.xhtml>.

U.S. Census Bureau. 2014. Geographic terms and concepts: Census divisions and Census regions. 3 Mar. 2014. <http:// www.census.gov/geo/reference/gtc/ gtc_census_divreg.html $>$.

U.S. Department of Agriculture. 2013. 2012 Fruit and tree nut yearbook. 13 Jan. 


\section{Research Reports}

2014. <http://usda.mannlib.cornell. edu/MannUsda/viewDocumentInfo. do?documentID=1377>.

Vaandrager, H.W. and M.A. Koelen. 1997. Consumer involvement in nutritional issues: The role of information.
Amer. J. Clin. Nutr. 65(Suppl. 6):1980S$1984 S$.

Visschers, V.H.M. and M. Siegrist. 2010 When reduced fat increases preference: How fat reduction in nutrition tables and numeracy skills affect food choices. Appetite 55(3):730-733.
Wassener, B. 2013. New data suggest a pause in China's slowdown. 13 Jan. 2014. <http://www.nytimes.com/ 2013/08/10/business/global/new-datasuggest-stabilizing-chinese-economy. html?_r=0 >. 